\title{
Is the dissipative behavior of river chemistry and catchment weathering dynamics reflected in their frequency distributions?
}

\author{
ROBERTA SAURO GRAZIANO ${ }^{1}$, AXEL KLEIDON ${ }^{2}$, \\ ANTONELLA BUCCIANTI ${ }^{1,3}$, DR. CATERINA GOZZI, \\ PHD $^{1}$, BARBARA NISI $^{3}$ AND ORLANDO VASELLI ${ }^{1,3}$ \\ ${ }^{1}$ University of Florence \\ ${ }^{2}$ Max Planck Institute for Biogeochemistry \\ ${ }^{3} \mathrm{CNR}-\mathrm{IGG}$ Institute of Geosciences and Earth Resources \\ Presenting Author: roberta.saurograziano@unifi.it
}

Waters and rocks are typical complex systems that play a key role in the global evolution since their interactions are able to dissipate chemical free energy. In order to understand such complexity, the shape of frequency distribution (normal, lognormal, power-law) has been investigated for long as indicator of the physical mechanisms generating concentration values. In this study, we aimed to link the differences in the scaling behavior with the dissipative behavior and entropy production within the system. Therefore, chemical observations from the Arno river basin (central Italy) were used to show how the state of disequilibrium between rainwater and continental crust drives the chemical weathering up to the catchment outlet, thus dissipating energy and producing entropy. Starting from the concept of entropy production by mixing of high TDS (total dissolved solids) groundwaters with river waters, we distinguished two groups of solutes that are reflecting not only differences in achieving the equilibrium (fast, step-wise) but also the correspondence with the shape of their frequency distribution (lognormal, power-law) and the entropy production rate. The compounds of the first group show a quite stationary state moving downstream, probably because of quickly reaching saturation $\left(\mathrm{Ca}^{2+}, \mathrm{HCO}_{3}^{-}\right)$or, on the contrary, a slow progression $\left(\mathrm{Mg}^{2+}, \mathrm{SiO}_{2}\right)$ and they are fitted by a lognormal model. The second group includes those chemical species which are characterized by a clear increasing trend along the river course $\left(\mathrm{Na}^{+}, \mathrm{Cl}^{-}, \mathrm{K}^{+}\right.$and $\left.\mathrm{SO}_{4}{ }^{2-}\right)$ and heavy tailed distributions. Our results indicate that such distinction is associated with different levels of energy dissipation according to the intensity of entropy production in the mixing processes: the former group presents low entropy production due to a scarcely dissipative mixing process with the groundwater. Instead, the latter has the highest entropy production rate and shows deviations from lognormal to power-law distributions, thereby representing the strongest dissipative behavior. Hence, this implies that 1) such deviations from lognormal scaling are likely indicative of enhanced dissipative behavior of river chemistry and 2) the frequency distribution approach could be applied to investigate the dissipative features of different natural systems under natural and anthropic forcing. 